\title{
Indirect effect of COVID-19 pandemic on maternal and neonatal health care in resource-poor setting
}

\author{
Reeta Bora1, Pranay Phukan $^{2 *}$, Kiran R. Konda ${ }^{2}$ \\ ${ }^{1}$ Department of Pediatrics and Neonatology, Assam Medical College, Dibrugarh, Assam, India \\ ${ }^{2}$ Department of Obstetrics and Gynecology, Assam Medical College, Dibrugarh, Assam, India
}

Received: 30 June 2021

Revised: 29 July 2021

Accepted: 30 July 2021

*Correspondence:

Dr. Pranay Phukan,

E-mail: pranayp4@yahoo.com

Copyright: $\odot$ the author(s), publisher and licensee Medip Academy. This is an open-access article distributed under the terms of the Creative Commons Attribution Non-Commercial License, which permits unrestricted non-commercial use, distribution, and reproduction in any medium, provided the original work is properly cited.

\begin{abstract}
Background: COVID-19 pandemic has been affecting maternal and neonatal health worldwide. Our study was done to find the indirect effect of the pandemic due to associated lockdown, travel restrictions, etc. on maternal and neonatal health in a rural resource-limited area in northeast India.

Methods: In this retrospective observational study, mothers of a rural, resource-limited area were enrolled if they delivered in the institution where the study was done. Hospital data regarding maternal mortality and stillbirth rate (SBR) from November 2019 till February 2020 (no-lockdown) was compared with the lockdown period (March 2020 till June 2020). Neonatal data of the no-lockdown and lockdown period were analysed and compared. All inborn and sick neonates delivered outside and admitted in the institution's neonatal unit after delivery (outborn) were included.

Results: There was a 33\% reduction of institutional delivery rate in Lockdown compared to the no-lockdown period. Outborn admission to the newborn unit was reduced by $41 \%$. Stillbirth and death due to perinatal events increased significantly (relative risk (RR) $1.45,95 \%$ CI: 0.85-2.48) amongst inborn in the lockdown period. During lockdown period maternal mortality increased from 551/100000 to 761/100000 live births (LB) (RR 1.38, 95\% CI: 1.21-1.52) and NMR from 26/1000 to 32/1000 LB (RR: 1.23, 95\% CI: 0.73-2.04).

Conclusions: Significant adverse indirect effect of COVID-19 pandemic is observed on maternal and neonatal health. Ways for avoidance of reversion of gain achieved in NMR and MMR in the last few years in lower and middle-income countries (LMIC) needs to be urgently looked at.
\end{abstract}

Keywords: COVID-19 pandemic, Indirect effect, Maternal and child health

\section{INTRODUCTION}

Maternal and neonatal health are true barometers of progress towards universal health coverage. ${ }^{1}$ Neonatal death accounts for almost $47 \%$ of under 5 mortality amounting to 7000 deaths/day. ${ }^{2}$ The figure indicative of loss of life becomes even higher if additional 1.3 million intrapartum stillbirths per year are included. ${ }^{3}$ Five years ago in 2014, every newborn action plan (ENAP) was initiated with evidence-based solutions to reduce neonatal mortality, clear roadmaps, specific targets, and milestones.
ENAP is aligned to the United Nations' sustainable developmental goal (SDG 3, target 3.2). ENAP aimed at a target of $<12 / 1000$ livebirth (LB) of neonatal mortality rate (NMR) by the year 2030, with an interim aim of $15 / 1000$ LB by $2020 .{ }^{4}$ Another goal of ENAP was to reduce stillbirth rate to $12 / 1000 \mathrm{LB}$ by 2030 with an interim of $14 / 1000$ LB by $2020 .{ }^{4}$ Lower and middle-income countries (LMIC) have been putting significant efforts to reduce NMR, stillbirth rate, and maternal mortality rate (MMR). Although still far away from the set goal, achievements had been considerable in last two decades. 
The COVID-19 pandemic has affected all countries worldwide. Recommendations for avoiding contact with COVID-19 (SARS-CoV2) virus remains same for pregnant women and newborn as for other population in a community. ${ }^{5}$ Transmission of infection to neonates has been more common through horizontal transmission although vertical transmission has also been reported. ${ }^{6-10}$ Although evidence is still evolving, at present it is suggested that pregnancy increases the severity of infection. ${ }^{11}$ But a major concern is that the pandemic's indirect ill effects may surpass the direct effect on maternal and neonatal health, especially in LMIC. ${ }^{12}$ The effect of prolonged periods of lockdowns, curfews, travel restrictions, disruption of staffing in healthcare facilities, elevated stress amongst health workers (HW) associated with the pandemic are factors that can affect the already weak healthcare systems in large populous countries. An analysis of 118 countries using the lives saved tool suggested that reductions in maternal and child health $(\mathrm{MCH})$ care coverage of around $15 \%$ for 6 months could result in 2,53,500 additional child deaths and 12,200 additional maternal deaths, while reductions of $\mathrm{MCH}$ care coverage around $45 \%$ for 6 months would result in additional 11,57,000 child deaths and 56,700 maternal deaths. $^{13}$

With India's $1^{\text {st }}$ case of COVID-19 being reported on $30^{\text {th }}$ January 2020, reporting became more frequent from March 2020. A nationwide lockdown was declared on $24^{\text {th }}$ March 2020 with the extension of this lockdown to months following it. During the lockdown period as a measure to prevent community spread of COVID-19, along with social distancing, contact tracing and tracking, quarantine of positive cases, there were also countrywide sealing of borders of towns, districts, and states, curfews, withdrawal of all forms of public transport and restriction on movement of private vehicles. These measures were important for saving lives but for the poor and marginalized communities, such measures increased their struggle for the maintenance of day-to-day life.

The institution where the study was done is located in one of the economically least developed Indian states and a state with one of the lowest ranks in the human development index. ${ }^{14,15}$ Thirty-three percent of the population, live below the government poverty line. ${ }^{16}$ Nearly $90 \%$ of the population availing $\mathrm{MCH}$ care in the institution where the study was done live below the poverty line with a daily earning of 3.8 USD. ${ }^{17}$ The population is rural, with a female literacy rate of $77.2 \%$ as per national family health survey (NFHS) 5 data. ${ }^{18}$ The institution provides referral obstetric services through comprehensive and emergency obstetrics service and neonatal care service, catering to almost 15 million population.

Annually 10,000-11,000 deliveries take place on average in the institution. With the efforts of government and nongovernment organizations, MMR and NMR have been reduced significantly in the state in the last decade but still is one of the highest in the country. The 85 bedded tertiary level NICU, provides free care to beneficiaries. A trained health worker (HW) attends each neonate at delivery. NICU transfer is based on predetermined criteria. Additional 1,500-2,000 sick out-born neonates are admitted annually. Neonatal data is recorded electronically, a few manually. During the study period, although screening was done, no pregnant women coming for delivery was found to be COVID-19 positive.

We aimed to find out the indirect effect of the COVID-19 Pandemic on maternal and neonatal health by retrospective analysis of records in a rural tertiary level teaching hospital, in Northeast India. Institutional deliveries in the country have been progressively increasing over the years. ${ }^{19}$ Hence comparison of data of the lockdown period was done with the no-lockdown period in the same year rather than comparing the same months of the previous year. The primary objective was to measure the effect of lockdown on maternal death, number of deliveries and neonatal admission rate to intensive care unit (NICU), neonatal morbidities, and mortality. The secondary objective was to observe, whether based on the availability of transportation facilities in communities availing the services of the hospital, these adverse effects varied.

\section{METHODS}

This was a retrospective observational study done at Assam Medical College, Dibrugarh, Assam over 8 months (November 2019 to June 2020). Data of all mothers who came for institutional delivery during the study period along with their new-borns were included. Data of outborn sick neonates who were admitted during the study period to the NICU were also included in the study.

The period from November 2019 to February 2020 was labelled "no-lockdown" period and between the period of March 2020 to June 2020 was labelled "lockdown" period. For both periods the data regarding number of deliveries, maternal deaths, stillbirth rate, live-birth (LB) rate, cesarean section (CS) rate, low birth weight (LBW <2500 gm birth weight) rate, prematurity ( $<37$ weeks gestational age) rate, resuscitation at birth in labour room (LR), Resuscitation failure (RF), NICU admissions, morbidities, mortality rate and causes of mortality was collected and compared.

Based on ethnicity, area of residence, and occupation, the maternal population attending the institution was divided into those belonging to ethnic local (group A) residing in villages with the main occupation being agricultural cultivation, indentured workers from tea-gardens (group $\mathrm{B})$, and immigrant population working as daily wage earners (group C). While groups $\mathrm{A}$ and $\mathrm{C}$ depend on government ambulances and public transport for travel to hospital, group B, working and residing in tea-garden have the facility of own primary health centres and ambulances in their tea-garden. Neonatal data in the 3 different communities were compared. 
Amongst outborn, the number of admissions, morbidities, and mortality during both periods were compared.

The institutional ethics committee approval was taken for the study and the data so collected was analysed using open epi info software. Intergroup differences were determined using t-tests for continuous variables and Chisquare tests for discrete-valued variables.

\section{RESULTS}

There were 4,155 deliveries from November 2019 till February 2020 (no-lockdown period) compared to 2,760 during March 2020 till June 2020 (lockdown period) showing a reduction of $33.5 \%$ in institutional deliveries during the lockdown. Of these, the number of live births was 4,065 in no-lockdown and 2,674 in the lockdown period. When compared to a similar period one year back (November 2018-February 2019), the number of deliveries increased by $11.3 \%$ in the no-lockdown period. In contrast, a decrease of the number of deliveries by $6.9 \%$ was observed in the lockdown period compared to a similar period of the previous year (March 2019-June 2019) (Figure 1).

The CS rate was $35 \%$ in the no-lockdown period, comparable to the previous year (37-41\%), increasing significantly in the lockdown period to $58.7 \%$. There was a $11.3 \%$ increase in hospital delivery rate in no-lockdown period as compared to similar period in previous year. This however declined by $33 \%$ in lockdown period (Figure 1). There was increase in Cesarean rate in lockdown period to $59 \%$ compared to $35-41 \%$ in other periods signifying increased attendance of complicated pregnancy in the hospital. MMR was $(\mathrm{N}=21 / 4,065) 516 / 100000 \mathrm{LB}$ in the no-lockdown period increasing to $(\mathrm{N}=19 / 2,674)$ $710 / 100000 \mathrm{LB}$ in the lockdown period, though statistically not significant (RR: $1.38 ; 95 \%$ CI: 1.21-1.52).

LBW rate including very low birth weight (VLBW), extremely low birth weight (ELBW), and prematurity rate were comparable in both periods (Table 1).

The number of stillbirths (RR: $1.45,95 \% \mathrm{CI}: 0.85-2.48$ ) and the number of neonates needing resuscitation at birth (RR: 1.23 ; 95\% CI: 1.05-1.43) were significantly higher in the lockdown period compared to the no-lockdown period. The total number of deaths due to resuscitation failure (RF) in LR was also increased in lockdown period (RR: 1.14; 95\% CI: 0.58-2.22). When all neonatal deaths due to perinatal events (stillbirth, RF, and NICU deaths due to birth asphyxia (BA)) were compared it was found to have increased significantly in the lockdown period compared to the no-lockdown period (RR: $1.38 ; 95 \% \mathrm{CI}: 1.2-1.5$ ) (Table 1).

Amongst inborn neonates, the total number of neonates needing NICU admission was lower in the lockdown period $(35.5 \%)$ compared to the no-lockdown period (38.4\%) (RR: 1.13; 95\% CI: 1.05-1.20). Admission for birth asphyxia (RR, 1.62; 95\% CI, 1.27-2.07) and sepsis (RR, 1.76; 95\% CI, 1.37-2.79) were significantly higher during lockdown period, while admission for neonatal jaundice (RR: 1; 95\% CI: 0.94-1.11) and prematurity with respiratory distress (RR: 1; 95\% CI: 0.70-1.53) were comparable. During the lockdown period, admissions for transient tachypnoea of newborn (TTN), hypoglycaemia, congenital malformations, surgical condition decreased significantly compared to the no-lockdown period (RR: 0.67; 95\% CI: 0.58-0.77).

NMR increased in the lockdown period significantly, $(32 / 1000 \mathrm{LB})$ as compared to the no-lockdown period (26/1000 LB) (RR: 1.23; 95\% CI: 0.73-2.04). Mortality amongst NICU admission increased from $5.5 \%$ in the nolockdown period to $7.4 \%$ in lockdown period (RR: 1.33 ; 95\% CI: 0.98-1.81). Deaths related to perinatal events in the institution increased significantly in lockdown period (RR: 1.38 ; 95\% CI: 1.2-1.5).

Inborn neonates were grouped into groups $\mathrm{A}, \mathrm{B}$, and $\mathrm{C}$ as mentioned in methodology. Of 4,065 live-births delivered in no-lockdown period, 1,696 (41.7\%) belonged to ethnic local villagers (group A), $1516(37.3 \%)$ to tea-garden workers (group B) and $853(21 \%)$ to immigrant population (group C). Along with the reduction of live-birth by $33 \%$, during lockdown period, the proportion of live-births contributed by different groups also changed. While group A's contribution to LB remained comparable, 1122 (42\%), that of by group B increased to $1168(43 \%)$ and that of group $\mathrm{C}$ reduced to $384(14.3 \%)(\mathrm{p}<0.001)$. In lockdown period, proportion of group B delivery increased $(\mathrm{p}<0.01)$ while that of their LBW delivery rate decreased owing to easy transportation facility for them, while for group $\mathrm{C}$ with difficulty in transportation, proportion of delivery decreased, while LBW rate and death rate increased significantly (Table 2).

The LBW rate amongst inborn neonates in both periods was comparable (32\% in no-lockdown versus $31.6 \%$ in lockdown). The proportion of contribution to LBW by group A (Ethnic local villagers) was comparable during both periods (no-lockdown $29.9 \%$ versus lockdown $30 \%$, (RR: 0.98; 95\% CI: 0.85-1.1). However, contribution by group B (tea-garden worker) to LBW reduced during lockdown period (no-lockdown $50.7 \%$ versus lockdown 43.9\%) (RR: 0.71 ; 95\% CI: 0.64-0.78) while contribution by group C (immigrant population) increased from $19.4 \%$ to $25.8 \%$ (RR: $2 ; 95 \%$ CI: $1.81-2.35$ ).

Amongst neonates who died in NICU, deaths in group A (no-lockdown, $\mathrm{N}=35$ versus lockdown, $\mathrm{N}=23$ ) (RR: 1; 95\% CI: 0.59-1.67) was comparable while in group B, during no lockdown periods (no-lockdown, $\mathrm{N}=42$ versus lockdown $\mathrm{N}=22$ ), it reduced (RR: 0.85; 95\% CI: 0.5-1.4), but death in group $\mathrm{C}$ significantly increased during lockdown period (no-lockdown period, $\mathrm{N}=10$ versus lockdown, $\mathrm{N}=16$ ) (RR: 3.55; 95\% CI: 1.62-7.76) (Table 2). 
Amongst outborn neonates, the number of admissions to NICU decreased significantly (by 41\%) in lockdown period compared to No-Lockdown period. Admission for LBW (RR: 0.99; 95\% CI: 0.81-1.1), prematurity (RR: 0.98; 95\% CI: 0.81-1.12) and neonatal jaundice (RR: 0.85;
95\% CI: 0.61-1.21) reduced during the lockdown period. Admission for birth asphyxia (RR: 1; 95\% CI: 0.83-1.3) and sepsis (RR: 1; 95\% CI: 0.84-1.2) however was comparable in both the periods. Mortality was $14.3 \%$ and $12.5 \%$ in lockdown period (RR: $1 ; 95 \%$ CI: 0.75-1.45).

Table 1: Changes in institutional delivery rate, sick neonate admission rate, NMR, MMR in no-lockdown and lockdown period.

\begin{tabular}{|c|c|c|c|}
\hline \multirow[b]{2}{*}{ Variables } & No-lockdown period N (\%) & Lockdown period N (\%) & \multirow{2}{*}{$\begin{array}{l}\text { Relative risk } \\
\text { (95\% confidence } \\
\text { interval) }\end{array}$} \\
\hline & $\begin{array}{l}\text { Total deliveries: } 4155 \text {, total } \\
\text { live birth: } 4065\end{array}$ & $\begin{array}{l}\text { Total deliveries: } 2760 \text {, } \\
\text { total live birth: } 2674\end{array}$ & \\
\hline \multicolumn{4}{|l|}{ LR data } \\
\hline Still birth & $91(22 / 1000 \mathrm{LB})$ & $86(32 / 1000 \mathrm{LB})$ & $1.45(0.85,2.48)$ \\
\hline Neonates needing resuscitation & $334(8.4)$ & $273(10.2)$ & $1.23(1.05,1.43)$ \\
\hline Neonates with resuscitation failure & $20(0.49)$ & $15(0.6)$ & $1.14(0.58,2.22)$ \\
\hline LBW (<2500 g BW) & $1338(32.9)$ & $846(31.6)$ & $1(0.90,1.11)$ \\
\hline Premature (<37 weeks GA) & $468(11.5)$ & $298(11.1)$ & $0.96(0.84,1.17)$ \\
\hline MMR & $551 / 100000 \mathrm{LB}$ & 761/100000 LB & $1.38(1.21,1.52)$ \\
\hline \multicolumn{4}{|l|}{ NICU data- inborn } \\
\hline Inborn NICU admission & 1561/4065 LB (38.4) & 951/2674 LB (35.5) & $1.13(1.05,1.20)$ \\
\hline NNJ & $761(48)$ & $476(50)$ & $1(0.94,1.11)$ \\
\hline $\mathrm{BA}$ & $123(7.8)$ & $113(11.9)$ & $1.62(1.27,2.07)$ \\
\hline Sepsis & $104(6.7)$ & $112(11.7)$ & $1.76(1.37,2.79)$ \\
\hline Prematurity with RDS & $63(4.0)$ & $40(4.2)$ & $1(0.70,1.53)$ \\
\hline $\begin{array}{l}\text { Other conditions (TTN, } \\
\text { hypoglycemia, malformations, birth } \\
\text { trauma, surgical conditions, etc.) }\end{array}$ & $510(32)$ & $210(22)$ & $0.67(0.58,0.77)$ \\
\hline Death in NICU & $87(5.5)$ & $71(7.4)$ & $1.33(0.98,1.81)$ \\
\hline NMR (NICU death+ RF/1000 LB) & 26 & 32 & $1.23(0.73,2.04)$ \\
\hline $\begin{array}{l}\text { Death due to perinatal events } \\
\text { (Stillbirth+RF+BA) }\end{array}$ & 197 & 172 & $1.38(1.2,1.5)$ \\
\hline \multicolumn{4}{|l|}{ NICU data- out born } \\
\hline Total outborn NICU admission & 573 & 335 (reduced by $41 \%$ ) & \\
\hline LBW & 356 & 208 & $0.99(0.81,1.1)$ \\
\hline Preterm & 166 & 96 & $0.98(0.81,1.12)$ \\
\hline BA with HIE & 154 & 98 & $1(0.83,1.3)$ \\
\hline Sepsis & 173 & 105 & $1(0.84,1.2)$ \\
\hline NNJ & 82 & 41 & $0.85(0.61,1.21)$ \\
\hline Death & 80 & 49 & $1(0.75,1.45)$ \\
\hline
\end{tabular}

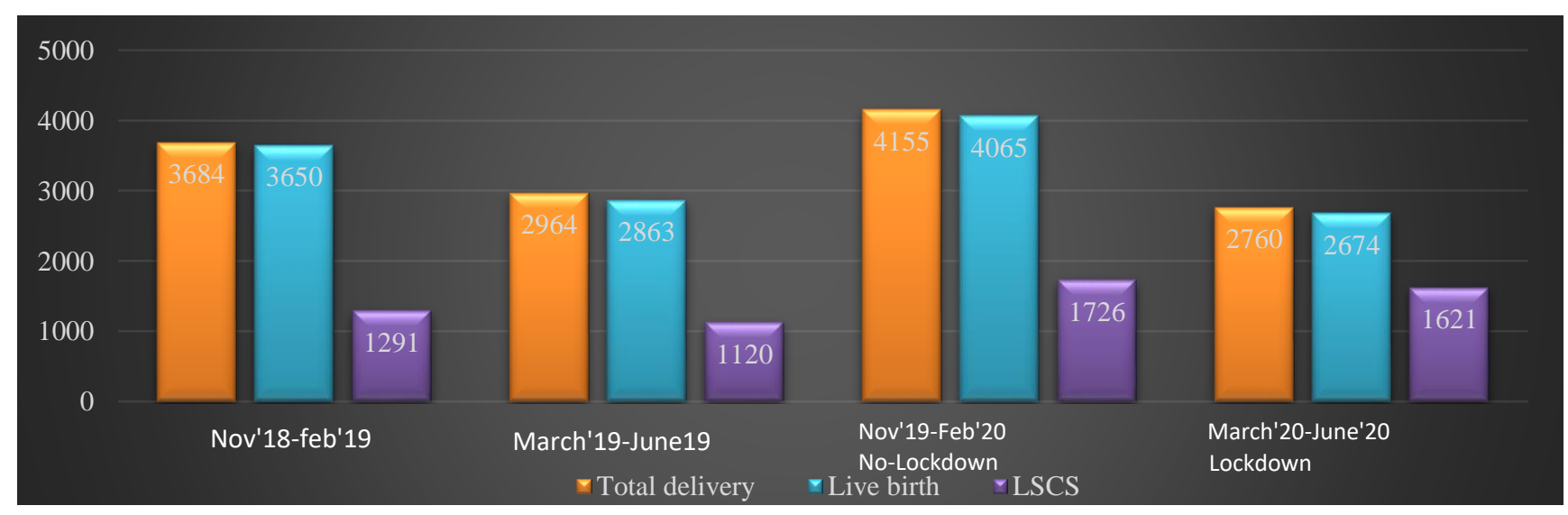

Figure 1: Number of deliveries, live birth and caesarean section in no-lockdown, lockdown period and in comparable periods in previous year. 
Table 2: Number of neonates delivered in no-lockdown and lockdown period amongst ethnic villagers (group A), tea industry worker (group B) and immigrant communities (group C) with proportion of LBW and death in them.

\begin{tabular}{|llll|}
\hline Parameter & $\begin{array}{l}\text { No-lockdown (November 19- } \\
\text { February 20) }\end{array}$ & $\begin{array}{l}\text { Lockdown (March 20- } \\
\text { June 20) } \\
\text { Total live births (LB): } \\
\mathbf{2 6 7 4}\end{array}$ & $\begin{array}{l}\text { Relative risk } \\
\text { (95\% confidence } \\
\text { interval) }\end{array}$ \\
\hline Group A & & $1122(42)$ & \\
\hline Livebirths n (\% of all LB) & $1696(41.7)$ & $259(30)$ & $1(0.85,1.1)$ \\
\hline LBW n (\% of all LBW) & $398(29.9)$ & $23(2)$ & \\
\hline Death n (\% of LB of group) & $35(2)$ & $1168(43.7)$ & $0.71(0.64,0.78)$ \\
\hline Group B & & $372(43.9)$ & $0.85(0.5,1.4)$ \\
\hline Livebirth n (\% of all LB) & $1516(37.3)$ & $23(1.8)$ & \\
\hline LBW n (\% of all LBW) & $679(50.7)$ & & $2(1.81,2.35)$ \\
\hline Death n $(\%$ of LB of group) & $35(2)$ & $384(14.3)$ & $3.55(1.62,7.76)$ \\
\hline Group C & & $219(25.8)$ & \\
\hline Livebirths n (\% of all LB) & $853(21)$ & $16(4.1)$ & \\
\hline LBW n $(\%$ of all LBW) & $261(19.4)$ & & \\
\hline Death n (\% of LB of group) & $10(1.1)$ & & \\
\hline
\end{tabular}

\section{DISCUSSION}

With the cumulative effort of government and nongovernment organizations, MMR, NMR and stillbirth rate had been declining significantly over the last 20 years worldwide. $^{20-22}$ World Health Organization declared COVID-19 a pandemic on $11^{\text {th }}$ March $2020 . .^{23}$ There are concerns about the indirect effect of the pandemic on maternal and neonatal health. Semaan et al mentioned that maternity care service is susceptible to reversal of the hardearned gains in health care utilization and use of evidencebased practices due to the pandemic. ${ }^{24}$ The indirect effect of the pandemic on maternal and neonatal health in LMIC has been tried to be assessed by using modelling approaches. Through modelling, Roberton et al estimated an increase in an additional 2,53,500 to $11,57,000$ under 5 mortality in children along with additional maternal deaths due to the indirect effect of pandemic. ${ }^{13}$ Similar conclusions were drawn by Riley et al. They estimated that even a moderate decrease of $10 \%$ in coverage of maternal and neonatal care could result in an additional 1,68,000 neonatal deaths and 28,000 maternal deaths globally. ${ }^{25}$

Most studies published till now have focused on the direct effect of the pandemic on maternal and neonatal health. A recent multicentric study from Nepal focused on the indirect effect of the pandemic on $\mathrm{MCH}$ care. ${ }^{26}$ Ours is the 1 st study from this part of the country in a very resource poor setting, that is trying to look at the indirect effect of the pandemic by analysing data retrospectively, comparing no-lockdown with lockdown period.

In our study, compared to the no-lockdown period, during the lockdown period, we observed a $33 \%$ reduction in the number of hospital deliveries. At the same time, there was an increase of the stillbirth rate (30/1000 LB) in lockdown period compared to no-lockdown period 922/1000 LB), with an increase in the cesarean section rate from $38 \%$ in no-lockdown to $58.7 \%$ in lockdown period. There was a significantly increased number of NICU admission for BA and sepsis compared to the no-lockdown period. These observations during the Lockdown period can be explained as resulting from travel delays due to sealing of borders between states and districts, curfews, financial constraints induced on marginally living families due to lack of daily wage-earning, an inability on their part to arrange transportation as well as poor hospital staffing due to some staff getting quarantined. Roberton et al in their three delays of care model had mentioned delay in travel as a cause of adverse outcomes in mothers and neonates. ${ }^{13}$ There was a significant decrease in number of NICU admission for conditions like hypoglycaemia, surgical condition etc during lock down period. Reduction in hospital delivery was seen in West Africa during Ebola virus outbreaks as an indirect effect of infection due to lockdowns and travel restrictions comparable with the present scenario. ${ }^{27}$ Effects of the pandemic on institutional delivery rate and stillbirth rate similar to our study were also observed by Ashish et al. ${ }^{26}$

NMR increased significantly from $26 / 1000$ LB in nolockdown period to $32 / 1000 \mathrm{LB}$ in lockdown period. An increase in NMR was also noted by Ashish et al in their study. The government and non-government organizations, aiming to achieve SDG goal 3 by 2030, had put significant effort for the reduction of NMR with notable gain in the last two decades. ${ }^{28}$ Hence an increase in NMR as an indirect effect of the COVID-19 pandemic is a great loss to the health sector.

It is important to note that both in no-lockdown and lockdown period, birth asphyxia had been the most important cause of death amongst inborn neonates, implying scope for improvement in maternal care, thereby reducing neonatal death due to perinatal events. An increase in neonatal deaths due to perinatal events in the lockdown period is alarming and needs urgent attention. Care of girl child and pregnant women, early identification 
of high-risk mothers, early referral, resuscitation facility at birth including trained personnel, availability of facilitybased neonatal care including adequately trained manpower with a facility for easy and prompt transportation of mothers with obstetrical emergencies are some requirements of the time.

We observed that during no-lockdown period, tea-garden workers' community (group B) contributed to $37.3 \%$ of all deliveries and $50.7 \%$ to all LBW. The high incidence of LBW in this community has been related to the high prevalence of maternal nutritional anemia in this community. ${ }^{29}$ In lockdown period, while contribution to total deliveries by group B increased from $37.3 \%$ to $43.7 \%$, contribution to LBW came down to $43.9 \%$ from $50.7 \%$. Mothers of group B, from tea-gardens had easy access to transportation by ambulance arranged by industry hospitals. This increase in the delivery rate in a group of population with easy access to transportation compared with the other two groups showcases the importance of easy availability of transportation facilities for the continuum of $\mathrm{MCH}$ care during lockdown in an epidemic/pandemic. A decrease in LBW rate in this group may be related to the fact that most pregnant women including those with normal pregnancy, may have been referred by health workers in industry hospitals, for fear of contacting COVID-19 from patients. During lockdown, while the contribution of group $\mathrm{C}$ (immigrant population) to livebirth was $10 \%$, their contribution to LBW and death increased very significantly. This group, comprising of daily wage earners, with families having no access to easy transportation and with loss of income during lockdown, possibly brought only the sickest mothers for institutional deliveries. Our findings thus highlight the importance of: maintaining grass-roots level $\mathrm{MCH}$ care, and provision for easy transportation of high-risk mothers free of cost during such lockdown, curfew, etc. during a pandemic to avoid its deleterious indirect effects on maternal and child health. There is a need for rebuilding the referral systems as well as reimagining ways of support so that the poorest of communities get due care during such times in resourcelimited areas.

Amongst out-born neonates, the admission rate to NICU for birth asphyxia and sepsis remained comparable in both lockdown period and no-lockdown period, while those for conditions like NNJ, LBW and prematurity decreased. Failure to transport extremely sick neonates or death while transportation is being arranged can be an explanation, again highlighting the importance of the facility for transportation especially during the time of public transport withdrawal.

As the effect of the pandemic was observed to differ on communities based on their easy accessibility to transportation, there is a need for ensuring such coverage of transportation facilities in all health facilities serving different types of communities based on place of residence and occupation.
A community survey to find: extent and method of coverage of pregnant women at home during lockdown by grass-root level workers, the number of home and local hospital deliveries, and outcome of deliveries will be very useful in assessing in detail the effect of lockdown.

Our findings thus confirm that the indirect effect of the pandemic on maternal and child health can be more severe than the direct effect as has been predicted in modelling studies. There is hence a need for formulating policies for the care of high-risk pregnant women during lockdowns, especially in resource-poor settings with a facility for free transportation. There is also an urgent need to formulate methods for the reversal of the loss in terms of healthcareseeking practices in communities due to the pandemic.

Our study was done in a period of time when community spread had not occurred yet in the state, but lockdown, curfew etc. were initiated for fear of community spread of the pandemic. During this period, screening of each pregnant woman was done before admission to the institution, but no mother was yet found positive for COVID-19. Hence the increase in NMR observed in this short period of study, indicates the harm done already on child health by the pandemic through indirect effect and not influenced by any of its direct effect.

Our study highlights that government policies for following each pregnant woman at home by grass root level workers, easy transfer of normal pregnant women to local health facilities, early recognition of high-risk women with provision for early transportation needs to be ensured during such lockdowns. Policymakers and program coordinators need to ensure coverage of transportation facilities in all communities of society.

The strength of our study is that our observations are relevant to all resource-poor areas i.e. LMIC, of the world.

Our study has the limitation of being a single-centre study for a short period. A multi-centric study would have given a better picture of the situation. Comparison of data from lockdown period with data of similar months in the previous year would have been ideal, but the institutional deliveries have been increasing in the past few years, hence comparison of data of the lockdown period was done with the no-lockdown period in the same year.

\section{CONCLUSION}

Our study results showed that the stillbirth and neonatal death related to perinatal events had increased significantly in the lockdown period. This has led to reversal of gains in maternal and neonatal mortality rates achieved through hard work over years. Based on the facility for easy transportation, the indirect effect of the pandemic varied in different communities. Hence, mothers referred for institutional deliveries and sick neonates needing facility care, require early referral with transportation facility. To avoid increase in NMR and 
MMR during the COVID-19 pandemic through its indirect effect, in LMIC, one way would be, to ensure transportation facilities for sick neonates and pregnant women by government and other agencies during periods of lockdown, curfew etc.

\section{Funding: No funding sources}

Conflict of interest: None declared

Ethical approval: The study was approved by the Institutional Ethics Committee

\section{REFERENCES}

1. HQSS, Lancet Global Health Commission on highquality health systems in the SDG era. Available at: http://www.hqscommission.org/. Accessed on 19 May 2019.

2. Dicker D, Nguyen G, Abate D, Abate KH, Abay SM, Abbafati C, et al. Global, regional, and national agesex-specific mortality and life expectancy, 1950 2017: a systematic analysis for the Global Burden of Disease Study 2017. The Lancet. 2018;392(10159):1684-735.

3. Blencowe H, Cousens S, Jassir FB, Say L, Chou D, Mathers C, et al. National, regional, and worldwide estimates of stillbirth rates in 2015 , with trends from 2000: a systematic analysis. The Lancet Global Health. 2016;4(2):98-108.

4. WHO \& UNICEF. Every Newborn Action Plan: Country Progress Plans and moving forward. ENAP Country Progress Tracking report. 2015.

5. ACOG/Clinical. Novel Corona Virus Practice Advisory, July 2020. Available at: https://www. acog.org/clinical/clinical-guidance/practiceadvisory/articles/2020/03/novel-coronavirus-2019. Accessed on 23rd August 2020.

6. Shahbazi Sighaldeh S, Ebrahimi Kalan M. Care of newborns born to mothers with COVID-19 infection; a review of existing evidence. The Journal of Maternal-Fetal \& Neonatal Medicine. 2020;1-3.

7. Karimi-Zarchi M, Neamatzadeh H, Dastgheib SA, Abbasi H, Mirjalili SR, Behforouz A, et al. Vertical transmission of coronavirus disease 19 (COVID-19) from infected pregnant mothers to neonates: a review. Fetal and Pediatric Pathology. 2020;39(3):246-50.

8. Kirtsman M, Diambomba Y, Poutanen SM, Malinowski AK, Vlachodimitropoulou E, Parks WT, et al. Probable congenital SARS-CoV-2 infection in a neonate born to a woman with active SARS-CoV-2 infection. CMAJ. 2020;192(24):647-50.

9. Vivanti AJ, Vauloup-Fellous C, Prevot S, Zupan V, Suffee C, Do Cao J, et al. Transplacental transmission of SARS-CoV-2 infection. Nature Communications. 2020;11(1):1-7.

10. Von Kohorn I, Stein SR, Shikani BT, Ramos-Benitez MJ, Vannella KM, Hewitt SM, et al. In utero severe acute respiratory syndrome coronavirus 2 infection. Journal of the Pediatric Infectious Diseases Society. 2020;9(6):769-71.
11. Allotey J, Stallings E, Bonet M, Yap M, Chatterjee S, Kew T, et al. Clinical manifestations, risk factors, and maternal and perinatal outcomes of coronavirus disease 2019 in pregnancy: living systematic review and meta-analysis. BMJ. 2020;370.

12. Menendez C, Gonzalez R, Donnay F, Leke RG. Avoiding indirect effects of COVID-19 on maternal and child health. The Lancet Global Health. 2020;8(7):863-4.

13. Roberton T, Carter ED, Chou VB, Stegmuller AR, Jackson BD, Tam Y, et al. Early estimates of the indirect effects of the COVID-19 pandemic on maternal and child mortality in low-income and middle-income countries: a modelling study. The Lancet Global Health. 2020;8(7):901-8.

14. Directorate of Economics and Statistics (2016-2017) Economic survey of Assam. Available at: https://des.assam.gov.in/information-services/econo mic-survey-assam. Accessed on 28 May 2021.

15. IAMR, Planning Commission Govt of India. India Human Development Report. 2018. Available at: https://niti.gov.in/planningcommission.gov.in/docs/p lans/stateplan/shdr.php?state=b_shdrbody.htm. Accessed on 28 May 2021.

16. Assam: Poverty, Growth \& Inequality - World Bank Document. Available at: https://documents1. worldbank.org/curated/en/545361504000062662/pdf /119141-BRI-P157572-Assam-Poverty.pdf. Accessed on 28 May 2021.

17. Latest minimum wages for shops and establishments in Assam. Available at: https://www.simpliance. in/minimum-wages/assam. Accessed on 28 May 2021.

18. National Health Family Survey 2019-20, Fact Sheet Assam. Ministry of Health and Family Welfare, Govt of India. Available at: http://rchiips.org/nfhs/NFHS5_FCTS/FactSheet_AS.pdf. Accessed on 28 May 2021.

19. Goudar SS, Goco N, Somannavar MS, Kavi A, Vernekar SS, Tshefu A, et al. Institutional deliveries and stillbirth and neonatal mortality in the Global Network's Maternal and Newborn Health Registry. Reproductive Health. 2020;17(3):1-9.

20. WHO, UNICEF, United Nations Population Fund, World Bank Group, United Nations Population Division. Trends in maternal mortality: 1990 to 2015. Geneva: World Health Organization, 2015. Available at: https://www.who.int/reproductivehealth/publicat ions/monitoring/ maternal-mortality-2015/en/. Accessed on 09 September 2020.

21. Blencowe H, Cousens S, Jassir FB, Say L, Chou D, Mathers C, et al. National, regional, and worldwide estimates of stillbirth rates in 2015, with trends from 2000: a systematic analysis. The Lancet Global Health. 2016;4(2):98-108.

22. UNICEF, WHO, World Bank, and UN. Level and trend of child mortality 2019. New York, NY: United Nations International Children's Emergency Fund, 2019. Available at: https://www.unicef.org/reports/ 
levels-and-trends-child-mortality-report-2019.

Accessed on 09 September 2020.

23. WHO, Regional Office for Europe/Health topics/Coronavirus disease (COVID-19) pandemic. Available at: https://www.euro.who.int/en/healthtopics/health-emergencies/coronavirus-covid-19.

Accessed on 23 August 2020.

24. Semaan A, Audet C, Huysmans E, Afolabi B, Assarag B, Banke-Thomas A, et al. Voices from the frontline: findings from a thematic analysis of a rapid online global survey of maternal and newborn health professionals facing the COVID-19 pandemic. BMJ Global Health. 2020;5(6):e002967.

25. Riley T, Sully E, Ahmed Z, Biddlecom A. Estimates of the potential impact of the COVID-19 pandemic on sexual and reproductive health in low-and middleincome countries. International Perspectives on Sexual and Reproductive Health. 2020;46:73-6.

26. Ashish KC, Gurung R, Kinney MV, Sunny AK, Moinuddin M, Basnet O, et al. Effect of the COVID19 pandemic response on intrapartum care, stillbirth, and neonatal mortality outcomes in Nepal: a prospective observational study. The Lancet Global Health. 2020;8(10):1273-81.

27. Delamou A, El Ayadi AM, Sidibe S, Delvaux T, Camara BS, Sandouno SD, et al. Effect of Ebola virus disease on maternal and child health services in Guinea: a retrospective observational cohort study. The Lancet Global Health. 2017;5(4):448-57.

28. Boerma T, Requejo J, Victora CG, Amouzou A, George A, Agyepong I, et al. Countdown to 2030: tracking progress towards universal coverage for reproductive, maternal, newborn, and child health. The Lancet. 2018;391(10129):1538-48.

29. Bora R, Sable C, Wolfson J, Boro K, Rao R. Prevalence of anemia in pregnant women and its effect on neonatal outcomes in Northeast India. The Journal of Maternal-Fetal \& Neonatal Medicine. 2014;27(9):887-91.

Cite this article as: Bora R, Phukan P, Konda KR. Indirect effect of COVID-19 pandemic on maternal and neonatal health care in resource-poor setting. Int J Reprod Contracept Obstet Gynecol 2021;10:353643. 